\title{
Dendritic cells and Brucella spp. interaction: the sentinel host and the stealthy pathogen
}

\author{
Eric Daniel Avila-Calderón ${ }^{1,2}$ • Leopoldo Flores-Romo ${ }^{1}$ - Witonsky Sharon ${ }^{3,4} \cdot$ Luis Donis-Maturano $^{5}$. \\ Miguel Angel Becerril-García ${ }^{6}$. Ma. Guadalupe Aguilera Arreola ${ }^{2} \cdot$ Beatriz Arellano Reynoso $^{7}$. \\ Francisco Suarez Güemes ${ }^{7}$. Araceli Contreras-Rodríguez ${ }^{2}$
}

Received: 31 July 2018 / Accepted: 6 February 2019/Published online: 19 February 2019

(C) Institute of Microbiology, Academy of Sciences of the Czech Republic, v.v.i. 2019

\begin{abstract}
As dendritic cells (DCs) are among the first cells to encounter antigens, these cells trigger both innate and T cell responses, and are the most potent antigen-presenting cells. Brucella spp., which is an intracellular facultative and stealthy pathogen, is able to evade the bactericidal activities of professional phagocytes. Several studies have demonstrated that Brucella can survive and replicate intracellularly, thereby provoking impaired maturation of DCs. Therefore, the interaction between DCs and Brucella becomes an interesting model to study the immune response. In this review, we first will describe the most common techniques for DCs differentiation in vitro as well as general features of brucellosis. Then, the interaction of DCs and Brucella, including pathogen recognition, molecular mechanisms of bacterial pathogenesis, and intracellular trafficking of Brucella to subvert innate response, will be reviewed. Finally, we will debate diversity in immunological DC response and the controversial role of DC activation against Brucella infection.
\end{abstract}

\section{Introduction}

Dendritic cells (DCs) are professional antigen (Ag)-presenting cells (APCs) distributed throughout an animal's body that exhibit major histocompatibility complex (MHC) on their surface and are a good source of pro-inflammatory cytokines such as IL-12 (Janeway and Medzhitov 2002). DCs are involved in two main roles: Ag uptake and processing and linking innate and adaptive immunity. Infectious agents and inflammatory products can induce DC activation, upon which DCs migrate to regional lymphoid tissue, such as lymph

Araceli Contreras-Rodríguez

aracelicontreras21@gmail.com

1 Departamento de Biología Celular, Centro de Investigación y de Estudios Avanzados, Instituto Politécnico Nacional, CINVESTAV-IPN, Av. IPN No 2508, Zacatenco, C.P 07330 Mexico city, Mexico

2 Departamento de Microbiología, Escuela Nacional de Ciencias Biológicas, Instituto Politécnico Nacional, Prolongación de Carpio y Plan de Ayala S/N, Santo Tomás, 11340 Mexico city, Mexico

3 Center for Molecular Medicine and Infectious Diseases/Center for One Health, Virginia-Maryland College of Veterinary Medicine, Virginia Tech, Blacksburg, VA 24061-0442, USA nodes, spleen, and Peyer's patches (Banchereau and Steinman 1998; Pulendran et al. 2001).

In peripheral tissues, DCs are present as immature cells with a poor capacity to stimulate $\mathrm{T}$ cells but are highly equipped to capture Ag (Banchereau and Steinman 1998). When immature DCs capture microbial agents or their products by phagocytosis, they travel away from the infection site and translocate to the $T$ cell areas of the proximal lymph nodes (Pulendran et al. 2001).

DCs interact with a variety of T cells and drive the immune response (Colonna et al. 2006). For instance, DCs expressing

4 Department of Large Animal Clinical Sciences, Virginia-Maryland College of Veterinary Medicine, Virginia Tech, Blacksburg, VA 24061-0442, USA

5 Departamento de Innovación Biomédica, Centro de Investigación Científica y de Educación Superior de Ensenada (CICESE), Carretera Ensenada-Tijuana 3918, Zona Playitas, 22860 Ensenada, Baja California, Mexico

6 Departamento de Microbiología, Facultad de Medicina, Universidad Autónoma de Nuevo León, Avenida Francisco I Madero y Dr. Aguirre Pequeño S/N Mitras Centro, 64460 Monterrey, Nuevo León, Mexico

7 Departamento de Microbiología e Inmunología, Facultad de Medicina Veterinaria y Zootecnia, Universidad Nacional Autónoma de México, Coyoacán, 04510 Mexico city, Mexico 
MHC-I interact with $\mathrm{CD} 8^{+} \mathrm{T}$ cells and induce a cytotoxic immune response, while $\mathrm{MHC}-\mathrm{II}^{+} \mathrm{DCs}$ interact with $\mathrm{CD} 4^{+}$ $\mathrm{T}$ cells and induce a mixed Th1/Th2 immune response (Itano et al. 2003; Mantegazza et al. 2013). $\mathrm{CD}^{+} \mathrm{T}$ cells, in the presence of mature DCs and IL-12, become interferon- $\gamma$ (IFN $\gamma$ )-producing T cells. IFN $\gamma$ activates microbicidal macrophage properties and promotes an inflammatory (Th1) response (Itano et al. 2003; Pulendran 2004). On the other hand, IL- 4 produced by DCs induces $\mathrm{CD} 4^{+} \mathrm{T}$ cells to differentiate into Th 2 cells. Th 2 cells secrete IL- 4 and IL- 5 and subsequently activate eosinophils as well as help B cells make Agspecific antibodies (Hochrein et al. 2000).

\section{Generation of DCs}

DCs originate in bone marrow from a common precursor for macrophages and DCs, the macrophage and DC precursor (MDP). MDP gives rise to the common DC precursor (CDP), which serves as a common progenitor for conventional DCs (cDCs) and plasmacytoid DCs (pDCs) (Poltorak and Schraml 2015).

In vivo, the development of all DCs is mostly dependent on FMS-like tyrosine kinase 3 ligand (FLT3L). In bone marrow, FLT3L acts on MDP and/or CDP and activates different transcription factor cascades to give rise to different $\mathrm{DC}$ subsets in a steady state (Poltorak and Schraml 2015). Granulocytemacrophage colony stimulating factor (GM-CSF) is the other important growth factor for DCs development. Although GMCSF does not have a major role such as FLT3L in DC development, it seems to balance DC subsets. For example, GM-CSF decreases pDCs and $\mathrm{CD} 8 \alpha^{+} \mathrm{DC}$ differentiation by blocking interferon regulatory factor-8 (IRF8) via signal transducer and activator of transcription-5 (STAT5) (Zhan et al. 2012a).

GM-CSF and FLT3L have been used to generate DC subsets in vitro. Bone marrow cells stimulated with recombinant FLT3L give rise to three DC subsets (referred to as FL-DCs): pDCs and 2 DC equivalents to the cDC subset. Although FLDCs do not express the same markers as their in vivo cDCs counterparts, they use the same transcription factors, produce similar cytokine and chemokine profiles, and have similar efficiencies for $\mathrm{Ag}$ presentation as splenic $\mathrm{CD} 8 \alpha^{+}$and/or CD8 $\alpha^{-}$DCs (Brasel et al. 2000; Naik et al. 2005).

Generally, GM-CSF is used in combination with IL-4 to generate immature DCs from peripheral $\mathrm{CD} 14^{+}$monocytes or bone marrow cells, and a further maturation step with a cytokine cocktail (TNF $\alpha$, IL-1 $\beta$, and/or IL-6) or bacterial-Ag is required to maintain a DC phenotype (Soruri and Zwirner 2005). GMCSF-derived DCs (referred as to GM-DCs) are equivalent to

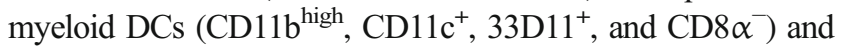
differentiation is independent of STAT3 (Zhan et al. 2012b).

GM-CSF plus IL-4 are broadly used for the generation of DCs; however, alternative methodologies such as the addition of inflammatory cytokines have been developed to obtain
DCs. For example, IL-15 allows the generation of DCs equivalents to GM-DCs from $\mathrm{CD} 14^{+}$monocytes without the use of GM-CSF (Saikh et al. 2001).

\section{DCs subsets}

Differences in surface marker molecules on DCs subsets might be indicative of differences in the nature of the $\mathrm{T}$ cell response (Pulendran et al. 1999). CD11c and MHC-II seem to be constitutively expressed in most DC subsets; however, these surface markers do not display all different phenotypes and functions of DC subsets. DC subsets are classified based on different phenotypic characteristics such as the expression of intracellular and surface markers, transcription factors used for their differentiation, and anatomic location (Schlitzer et al. 2015).

In the mouse, two well-characterized $\mathrm{cDC}$ subsets have been described: the $\mathrm{cDC} 1$ subset includes DCs expressing $\mathrm{CD} 8 \alpha^{+}$(in lymphoid organs) or CD103 (in peripheral organs), while the $\mathrm{CDC} 2$ subset is comprised of $\mathrm{CD} 4^{+} \mathrm{CD} 11 \mathrm{~b}^{+} \mathrm{DCs}$ in the spleen and $\mathrm{CD} 24^{+} \mathrm{CD} 11 \mathrm{~b}^{+} \mathrm{DCs}$ in nonlymphoid tissues such as the lung, intestine, and dermis. The $\mathrm{CDC} 1$ subset requires IRF8 and is the only group that expresses Toll-like receptor 3 (TLR3), whereas $\mathrm{cDC} 2$ subsets require transcription factors such as IRF4. Phenotypic and functional studies have revealed similarities between mouse and human cDCs; in humans, $\mathrm{CD} 141^{+} \mathrm{DCs}$ and $\mathrm{CD} 1 \mathrm{c}^{+} \mathrm{DCs}$ resemble mouse cDC1 and cDC2, respectively (Guilliams et al. 2014; Schlitzer et al. 2015).

pDCs are the other major subset of DCs that develop from the CDP in bone marrow. pDCs belong to a different lineage of DCs; pDCs express B220, CD303, CD304, and CD123 and produce large amounts of type-1 interferon (IFN- $\alpha$ ) (IFN-producing cells or IPCs) (Seillet and Belz 2013).

In lymphoid and nonlymphoid tissues, different subsets of DCs have been found. For example, in the spleen, two separate subsets of DCs have been described: lymphoid DCs (CD $8 \alpha^{+}$ $\mathrm{CD} 11 \mathrm{~b}^{-} \mathrm{CD} 205^{+} \mathrm{CD} 24^{+}$; referred to as $\left.\mathrm{CD} 8 \alpha^{+}\right)$located at the $\mathrm{T}$ cell zone in the spleen and myeloid DCs $\left(\mathrm{CD} 8 \alpha^{-} \mathrm{CD} 11 \mathrm{~b}^{+}\right.$ $\mathrm{CD} 24^{+} 33 \mathrm{D} 1^{+}$; referred to as $\mathrm{CD} 8 \alpha^{-}$) in the red pulp at the marginal zone. These DCs subsets not only differ in their surface markers and location but also in their capacity to process $\mathrm{Ag}$ and cytokine production; (i.e., IL-12 production is restricted to lymphoid DCs) (Hey and O'Neill 2012).

DCs take up and process a great variety of Ags, including those derived from bacterial pathogens. Once DCs process bacterial Ags, they trigger different signaling pathways to induce the appropriate immune response. However, bacterial pathogens, especially those able to live in an intracellular niche, have developed a plethora of strategies to subvert DC responses. Here, we focused especially on the interaction between the bacterial pathogen Brucella spp. and DCs.

Brucella species are intracellular facultative Gram-negative pathogens that reside inside various host cell types, including 
DCs. Brucella species avoid the host immune response by utilizing several clever strategies such as avoiding intracellular destruction mechanisms and inhibiting DC maturation, $\mathrm{Ag}$ presentation, and $\mathrm{T}$ cell activation (de Figueiredo et al. 2015). Thus, DCs could serve as a model to understand the Brucella pathogenesis and to identify new targets for vaccine development against brucellosis. In the following sections, we describe some important characteristics of the interaction between Brucella spp. and DCs.

\section{The stealthy pathogen: Brucella spp.}

Brucella species are facultative intracellular Gram-negative bacteria, noncapsulated and nonspore-forming. Brucella causes the zoonosis named brucellosis, also known as Malta fever. Brucellosis is endemic in many countries of the world, including Latin America, the Middle East, Africa, Central Asia, and the Mediterranean (Pappas et al. 2006).

To date, 11 Brucella species have been described and classified according to the preferred animal host: $B$. melitensis (sheep and goats), B. abortus (cattle), B. suis (swine), B. canis (dogs), B. ovis (sheep) and B. neotomae (woodrats), $B$. ceti (dolphins, porpoises and whales), and $B$. pinnipedialis (seals) (Pappas 2010). In the last few years, new species have been found in different sources: $B$. microti was found in voles and foxes, B. inopinata was isolated from a breast implant infection, and recently, $B$. vulpis was isolated from red foxes (Scholz et al. 2008, 2010, 2016).

\section{Brucellosis: general features}

\section{Acute and chronic brucellosis}

In both humans and animals, Brucella targets the mucosa mainly through the respiratory epithelium or conjunctiva, and then the bacterium is internalized by phagocytes leading to systemic dissemination. However, little is known about the specific cells that allow bacterial internalization.

In humans, Brucella infection is mainly acquired through the ingestion of unpasteurized dairy products containing the bacteria; unpasteurized cheese and raw milk are commonly involved in brucellosis outbreaks in underdeveloped countries. Brucellosis is associated with some occupational groups such as farmers, veterinarians, ranchers, and meat-packing employees who may have contact with sick animals (Seleem et al. 2010).

The clinical manifestations of human brucellosis comprise nonspecific symptoms; the most common include undulant fever, myalgia, arthralgia, chills, headache, and weakness. Approximately $10-30 \%$ of brucellosis patients will develop chronic infection and/or some complications such as spondylitis, arthritis, endocarditis, or neurobrucellosis (Dean et al. 2012; Guzmán-Hernández et al. 2016). In animals, Brucella causes spontaneous abortion, stillbirths, and decreased fertility and milk production in females, whereas males experience orchitis, epididymitis, and fertility issues (Seleem et al. 2010).

Brucella evades the innate immune response, impairing DC maturation and subverting macrophage and neutrophil killing; indeed, Brucella resists and survives the bactericidal actions of neutrophils but does not replicate inside these cells (Barquero-Calvo et al. 2007). At the initial stage of infection, Brucella induces an adaptive immune response involving the microbicidal activity of macrophages (activated by IFN- $\gamma$ of $\mathrm{CD}^{+}$and $\mathrm{CD} 4^{+} \mathrm{T}$ cells), and then infected macrophages are eliminated by cytotoxic T cells, and Brucella opsonization/ phagocytosis is induced by IgG antibodies (Ahmed et al. 2016). In the case of chronic brucellosis, $\mathrm{CD}^{+}$and $\mathrm{CD} 25^{+}$ $\mathrm{T}$ cells increase in the spleens of infected mice, which exert an immunosuppressive state regulating $\mathrm{T}$ cell activity. In patients with chronic brucellosis, high levels of TGF- $\beta$ have been found in their sera, and furthermore, no $\mathrm{T}$ cell proliferation after stimulation with Brucella antigens has been observed, indicating suppressed $\mathrm{T}$ cell function mediated by TGF- $\beta$ (Elfaki and Al-Hokail 2009). The chronicity of brucellosis is due to Brucella's ability to survive inside professional phagocytic cells and to evade the host immune response. Brucella can infect different cell types, including epithelial cells, trophoblasts, B cells, DCs, macrophages, synoviocytes, and T cells (Baldwin and Goenka 2006; Giambartolomei et al. 2017; Goenka et al. 2012; Velásquez et al. 2012). Brucella persistence occurs in mononuclear phagocytic system tissues, but the bacteria can also be found in reproductive organs, bones, and joints (Ahmed et al. 2016). Once infection is established, Brucella uses infected cells as a replicative niche and reservoir, inhibiting apoptosis and promoting chronic infection (Baldwin and Goenka 2006). Omp31 from B. melitensis contributes to the apoptosis inhibition induced by TNF $\alpha$ in RAW264.7 macrophages by the classical and mitochondrial pathway (Zhang et al. 2016), while B. abortus induces the A20 protein in RAW264.7 macrophages and promotes apoptotic pathway inhibition (Wei et al. 2015).

In mice infected with Brucella, the spleen is the main organ in which the pathogen persists. Susceptible IL-12p40 KO (Knock out)-mice infected intranasally with $B$. melitensis showed spleen infection after 28 days postinoculation. The bacteria were located in T cells on the white pulp of the spleen, and the main cells harboring Brucellae were cells resembling M2a macrophages. These reservoir cells infected with Brucella expressed $\mathrm{CD} 11 \mathrm{c}^{+}, \mathrm{CD} 205^{+}$, and $\mathrm{Arg} 1^{+}$; these markers were observed also in lung cells infected with Mycobacterium tuberculosis (Hanot Mambres et al. 2015). The deficient Th1 response in KO mice favoring the differentiation of the M2a macrophages population is indicative of a 
Th2 environment. Previously, Xavier et al. found that M2a macrophages were induced during chronic infection provoked by $B$. abortus; interestingly, macrophages containing high numbers of bacteria were observed (Xavier et al. 2013). Because M2a macrophage polarization is induced by IL-4/ IL-13 via STAT6, bacterial colonization in the spleen and impairment of M2a macrophage surface markers in double KO mice (IL-12p $40^{-/-}$STAT6 $^{-1}$ ) were expected. However, Hanot-Mambres et al. found that neither Brucella infection in

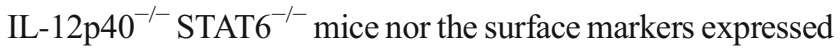
in macrophages were affected. Based on the observations of Xavier et al. and Hanot-Mambres et al., it is probable that myeloid cells are the critical reservoir in the spleen that may promote chronicity during brucellosis.

\section{Pathophysiology of brucellosis}

There is controversy over the ability of Brucella to invade multiple sites of the gastrointestinal tract; for example, B. abortus has been isolated from the gastrointestinal tracts of calves previously infected by the oral route with spiked milk (Carpenter 1924). Additionally, Rossetti et al. inoculated B. melitensis $\left(3 \times 10^{9} \mathrm{UFC}\right)$ in the intestinal loops of calves, and while the bacteria were recovered after 15-min and 12-h postinoculation in the Peyer's patches, no histopathological damage was observed in the tissue (Rossetti et al. 2013). On the other hand, von Bargen et al. showed that mice infected with $B$. melitensis $16 \mathrm{M}\left(10^{9}\right.$ bacteria) by the oral route induced the formation of granulomas composed of epithelioid cells and a few neutrophils in the cervical lymph nodes (CLN), although no dissemination was observed (von Bargen et al. 2015).

At the onset of Brucella infection in mice (from 0 to 2 days postinfection), there are no morphological or cell distribution changes in the spleen; additionally, the bacteria may be detected in the liver at the sinusoids inside the Kuppfer macrophages. In the acute phase (from the third day to the secondthird week postinfection) the number of bacteria increases in the organs, and cell infiltration is apparent. In the liver, granulomas are evident in the first week after infection; granulomas are composed of macrophages and DCs, accompanied by plasma cells and lymphocytes (de Figueiredo et al. 2015; Grilló et al. 2012; Yoneyama and Ichida 2005). The spleen in the acute phase, after the first week of infection, shows increased size with macrophage and neutrophil infiltration, while the bacterial burden remains constant (Enright et al. 1990). At the end of the acute phase, the numbers of macrophages, neutrophils, and B and T cells increase slightly, as well as levels of IL-12, IL-6, and IFN $\gamma$ (Grilló et al. 2012; Murphy et al. 2001). In the chronic phase (ranging from 8 to 11 weeks postinfection), granuloma size in the liver increases, and multinucleated giant cells and polykarions are observed in the centers of the granulomas (Cheville et al. 1995). Similarly, granuloma number and size in the spleen increase. The initial chronic brucellosis phase starts around the second-third week, and bacterial burden slowly decreases at approximately 75 days postinfection. Moreover, splenomegaly decreases, and macrophage infiltration is reduced (Enright et al. 1990; Grilló et al. 2012); however, the liver shows clearance at approximately 3-4 weeks postinfection, whereas the spleen is highly colonized during the chronic stage (Grilló et al. 2012).

\section{From outside to inside: how do DCs allow Brucella entry?}

Once ingested, Brucella spread during transport through the digestive tract. Some research has focused on studying oral infection of Brucella in vivo. One such report by Rossetti et al. involved healthy calves infected with $10^{9} \mathrm{CFU}$ of B. melitensis in the distal jejunum and ileum (ligated ileal loop model). The authors demonstrated that $B$. melitensis modulates inflammatory responses, limiting intestinal histopathological lesions, invading Peyer's patches, and disseminating to the mesenteric lymph nodes to induce bacteremia (Rossetti et al. 2013). Likely, Brucella translocates through the mucosal epithelium and is taken up by the DC subset present in the subepithelial dome of the ileal Peyer's patch. This DC subset secretes high levels of lysozyme (termed LysoDCs) and is highly efficient at capturing Salmonella enterica serovar Typhimurium (hereafter referred as S. typhimurium) (Lelouard et al. 2010, 2012); however, further investigation is needed to clarify whether LysoDCs are involved in Brucella uptake.

In a retrospective study analyzing patients diagnosed with brucellosis acquired via the ingestion of unpasteurized contaminated dairy products, most bacteria were found in the cervical lymph nodes (CLNs) (43-83\%) and occasionally disseminated to other organs. CLNs drain the oral cavity, and most of the bacteria acquired by the oral route reach this regional lymph node (von Bargen et al. 2015; Yamazaki et al. 2012). Upon arrival at the CLNs, bacteria are captured or disseminated. Therefore, CLNs represent an efficient trap and reservoir for pathogens able to cause chronic infections, and the tissues drained by CNLs are the most successful route of entry to the host for pathogens acquired orally. As mentioned above, ingestion of unpasteurized contaminated dairy products is the most common route by which people acquire Brucella infection; however, it has been demonstrated experimentally that this is not the most efficient route since the bacterial burden required to infect mouse ranges from $10^{9}$ to $10^{11} \mathrm{CFU}$. In infections caused by pathogens transmitted via the oral route, regional lymphadenitis is more common than diarrhea, indicating that the upper mucosa is the normal site of entry for these pathogens instead of the gastrointestinal tract. Taking into consideration these observations, it has been proposed that Brucella is not a proper enteropathogen (Gorvel et al. 2009; von Bargen et al. 2015). 
Another report described the oral infection of mice with B. melitensis $16 \mathrm{M}\left(10^{9}\right.$ bacteria/mouse) using spiked milk. Oral infection led to early colonization of the CLN, where Brucella proliferated and persisted up to 50 days postinfection (chronic steady state). Moreover, local inflammation with upregulation of IFN $\gamma$ and monocyte/macrophage was observed, but DC infiltration was not (von Bargen et al. 2015).

Under steady-state condition, the airways and trachea contain four specific DC subsets: intraepithelial DCs $\left(C D 11 c^{\text {high }}\right.$ $\mathrm{CD} 11 \mathrm{~b}^{\text {low }} \mathrm{CD}_{103^{+}}$), DCs localized at the submucosa $\left(\mathrm{CD} 11 \mathrm{~b}^{\text {high }} \mathrm{CD} 103^{-} \mathrm{CD} 11 \mathrm{c}^{\text {high }}\right)$, monocytic DCs $\left(\mathrm{CD} 11 \mathrm{~b}^{\text {high }}\right.$ $\mathrm{CD}_{103^{-}} \mathrm{MHC}^{-\mathrm{II}_{-}^{+}}$), and pDCs. Intranasal infection of mice with $S$. typhimurium increases the percentage of DCs located at the submucosa level, whereas intraepithelial DCs decrease. However, both of these DC subsets upregulate the expression of costimulatory molecules such as CD80 and CD86, indicating clear activation of the immune system in the lung. Since Brucella is considered highly infectious, the inhalation of Brucella aerosols from aborted placenta or through laboratory exposures also leads to infection. In the case of the intranasal route, mice inoculated intranasally with $5 \times 10^{5} \mathrm{~B}$. abortus 2308 were compared with a group of mice infected with $S$. typhimurium. The results showed that pulmonary B. abortus infection did not change the distribution of pulmonary DC subsets in the lung nor upregulate the expression of costimulatory molecules from $24 \mathrm{~h}$ up to 5 days postinfection (onset to acute infection) (Archambaud et al. 2010; del Rio et al. 2010; Smither et al. 2009; Traxler et al. 2013; Vermaelen and Pauwels 2005).

Alveolar macrophages have a major role in protecting against $B$. abortus 2308 infection; macrophages inhibit DC action, and only when the macrophages are overwhelmed will DCs interact with the pathogen. Upon partial macrophage depletion, the induction of inflammatory response by DCs was observed (Archambaud et al. 2010). Brucella was able to survive and replicate inside macrophages and DCs; alveolar macrophages along with DCs transport Brucella to the mediastinal lymph node, contributing to the dissemination of infection from the lung to other parts of the infected host (de Figueiredo et al. 2015).

Another common route for Brucella infection in humans and animals linked to bacterial aerosols is the conjunctival route. Although the eye is considered an immune-privileged organ, a subset of immature and mature DCs were found in the human and mouse cornea, at the epithelium and stromal zone. At the normal cornea, cDCs and Langerhans DCs have been observed: $\mathrm{CD} 141^{+}(\mathrm{cDC} 1)$ and $\mathrm{CD} 1 \mathrm{c}^{+}(\mathrm{cDC} 2)$ in humans and $\mathrm{CD} 103^{+}(\mathrm{cDC} 1)$ and $\mathrm{CD} 11 \mathrm{~b}^{+}(\mathrm{cDC} 2)$ in mice (Knickelbein et al. 2009, 2014). However, it is not clear which DC subset is involved in Brucella infection. Although the conjunctiva is a less common route of natural infection with Brucella, this route has been used for vaccination to control caprine and ovine brucellosis, employing a B. melitensis Rev. 1 live vaccine (Blasco 1997). The conjunctiva is related to the conjunctiva-associated lymphoid tissue (CALT); an interconnection in the mucosal system allowing a distal immune mucosal response when the local mucosa is stimulated has been demonstrated, and $\mathrm{M}$ cells might be involved in the translocation of antigens (Pulendran and Ahmed 2011). For example, when sheep were infected by the conjunctival route with $5 \times$ $10^{7} \mathrm{CFU}$ of virulent $B$. melitensis $\mathrm{H} 38$, the animals developed acute systemic brucellosis located in the peripheral lymph nodes but eradicated the bacteria at the local site of inoculation (Suraud et al. 2008).

\section{DCs-Brucella interaction}

The first step in establishing an intracellular lifestyle is entry of the bacterium into host cell, followed by avoidance of any intracellular destruction mechanisms. Some Brucella surface molecules are involved in host cell entry. One of these molecules is the SP41 protein, found in B. melitensis, B. abortus, and B. suis; SP41 is encoded by the BMEI0216 locus from B. melitensis $16 \mathrm{M}$, and its function is to mediate entry of the pathogen into epithelial cells (Castañeda-Roldán et al. 2006; Hernández-Castro et al. 2008). Moreover, the efp gene and the pathogenicity island Bab1_2009-2012 from B. abortus promote adhesion and internalization into macrophage and epithelial cells (Czibener and Ugalde 2012; Iannino et al. 2012).

Inside host cells, especially DCs, Brucella modulates the expression of surface molecules related to maturation, costimulation, migration and/or $\mathrm{Ag}$ presentation, as well as influences cytokine production (Billard et al. 2007a; Elfaki et al. 2015; Fabrik et al. 2013).

There is contradictory information in the literature regarding the effects of Brucella on DC maturation/activation. Therefore, we divided the following section into two parts: the first will show evidence of DC activation/maturation by infection/stimulation with Brucellae or their antigens (outer membrane proteins (OMPs), lipopolysaccharide (LPS) or heat-killed bacteria), and the second part will describe reports demonstrating impaired activation/maturation. Moreover, we include a table which summarizes all these findings (Table 1).

\section{Evidence of DC activation/maturation}

Zwerdling et al. (2008) observed the activation and maturation of GM-DCs infected with $B$. abortus. Infected GM-DCs upregulated CD80, CD83, CD80, CD40, CCR7, MCH-II, and MHC-I surface molecules and induced cytokines such as IL-6, IL-10, IL-12, and TNF $\alpha$ (required for the induction and modulation of adaptive immune response). GM-DC maturation was independent of bacterial viability since heat-killed $B$. abortus (HKBa) induced upregulation of costimulatory molecules, 


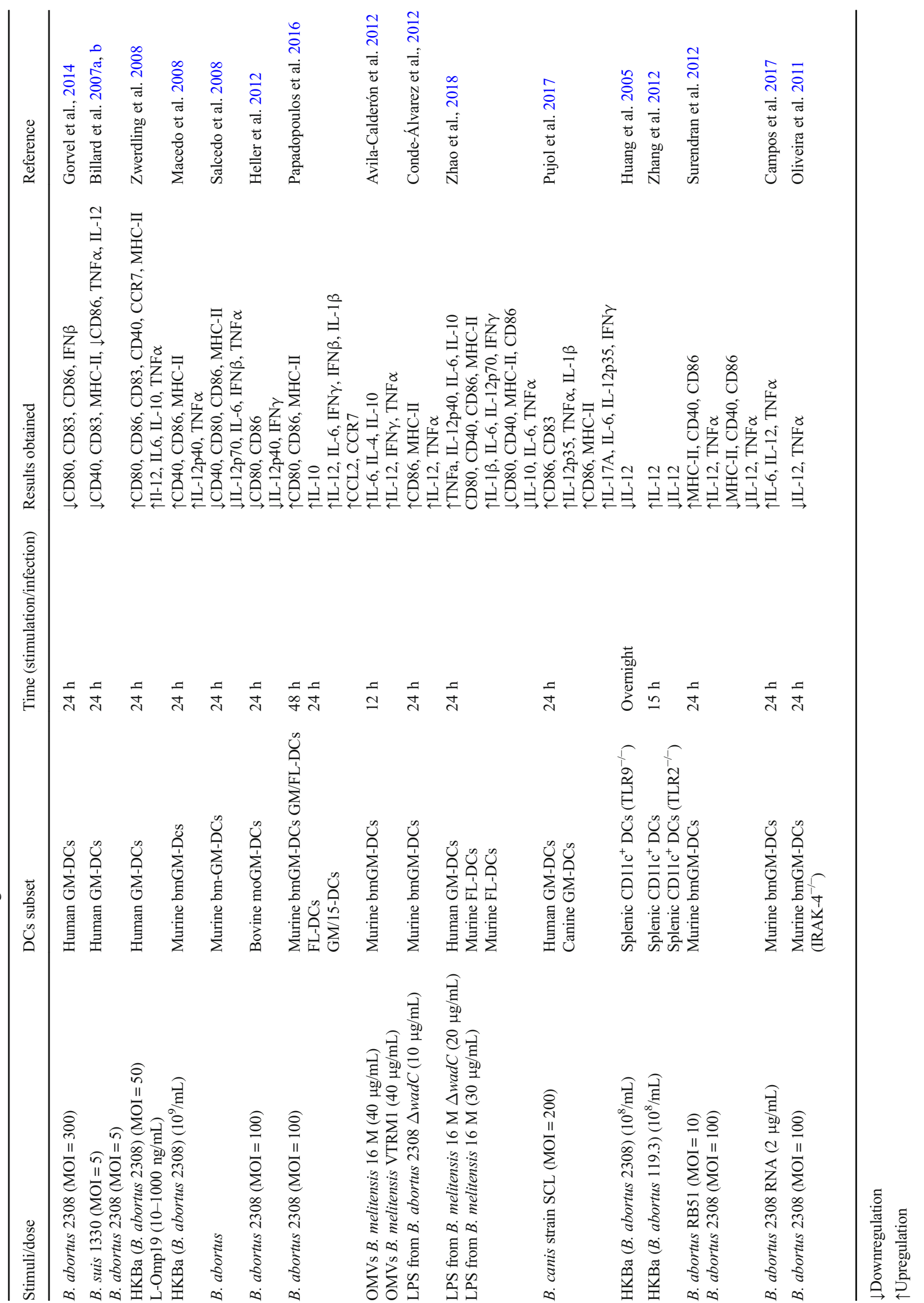


chemokines receptors, and cytokines. GM-DCs maturation was attributed to Brucella lipoproteins; GM-DCs stimulated with lipidated Omp19 induced the upregulation of surface molecules and cytokines, whereas purified B. abortus LPS or unlipidated Omp19 did not (Zwerdling et al. 2008).

Using murine bone marrow-derived DCs (differentiated with GM-CSF plus IL-4; referred as bmGM-DCs), Macedo et al. observed the upregulation of costimulatory molecules (CD40 and CD86), MHC-II, as well as significant cytokine production (TNF $\alpha$ and IL-12p40) at 24-h poststimulation with $\mathrm{HKBa}$ relative to unstimulated cells (Macedo et al. 2008).

B. melitensis, B. abortus, and B. suis are the main species causing infection in humans and are mainly transmitted zoonotically (Guzmán-Hernández et al. 2016). A large number of studies have focused on these Brucella species and their interactions with the host due to the importance, incidence/ frequency, and virulence of infection. Compared with the three species mentioned above, B. canis and B. ovis are the only two natural rough Brucella species that infect their animal host. B. canis, with a lower incidence of human cases, also represents a public health risk; however, until now, no studies examining its interaction with DCs have been reported (Marzetti et al. 2013). In humans, B. canis causes a mild or asymptomatic infection, whereas in dogs, like other animals, brucellosis induces abortion in females and epididymitis/ orchitis in males, as well as some complications such as diskospondylitis (Wanke 2004). It is possible that differences in human and canine brucellosis may be attributed to differences in the immune response. When infected with $B$. canis, human and canine GM-DCs upregulate the expression of CD86, CD83, and class II molecules 24-h postinfection. On the other hand, cytokine gene profile expression differs: while canine GM-DCs overexpress IL-17A, IL-6, IFN $\gamma$, IL-12p35, human GM-DCs overexpress IL-12p35, TNF $\alpha$, and IL-1 $\beta$. At the protein level, the cytokine profiles are very similar; high production of INF $\gamma$ and IL-17A in canine GM-DCs and IL-12 and TNF $\alpha$ in human GM-DCs. Clearly, B. canis elicits a Th1 response in human GM-DCs that is essential for the pathogen eradication, and this is likely the reason symptoms in humans are less severe. GM-DCs infected with B. canis, elicit a Th1/Th17 cytokine profile (Pujol et al. 2017). The role of the Th17 response in brucellosis is not clear yet; IL-17 has been implicated in osteoarticular complications in brucellosis. Additionally, Th17 cells producing IFN $\gamma / \mathrm{IL}-17$ are related to inflammatory disorders (Giambartolomei et al. 2017). Another intracellular pathogen, M. tuberculosis induces a combined Th1/Th17 response and the formation of granulomas (Bystrom et al. 2015; Lyadova and Panteleev 2015). It is likely that the IFN $\gamma /$ IL-17 cytokine profile elicited by $B$. canis in canine DCs is associated with osteoarticular complications in dogs such as diskospondylitis.
Evidence of impaired DC activation/maturation

Despite the stealthy ability of Brucella to reside inside professional phagocytes and impair the immune response, the role of Brucella in DCs activation/maturation seems to be contradictory. Human monocyte-derived GM-DCs infected with smooth $B$. suis or B. abortus decreased the expression of maturation surface markers (chemokine receptor CCR7, CD83), costimulatory molecules (CD86, CD40), and MHC-II relative to GM-DCs infected with rough mutants. Moreover, Brucella infection decreased Ag presentation, as well as the production of the inflammatory cytokines IL-12 and TNF $\alpha$ (Billard et al. 2007b). TNF $\alpha$ is essential for DC maturation; in a previous report, $B$. suis Omp25 impaired TNF $\alpha$ production on THP-1 monocytes (Jubier-Maurin et al. 2001). Recently, it was demonstrated that B. suis Omp25 dysregulates microRNA expression on porcine alveolar and murine macrophages, leading to the inhibition of NF-KB signaling and TNF $\alpha$ suppression (Billard et al. 2007b; Luo et al. 2018). The decrease in inflammatory cytokines and the poor T cell stimulation of Brucellainfected GM-DCs avert the induction of a Th1 immune response, which is essential for eradicating intracellular bacteria (Billard et al. 2007b).

Salcedo et al. (2008) observed decreased expression of CD40, CD80, CD86, MHC-II, and low cytokine concentrations of IL-12p70, TNF $\alpha$, IL-6, and IFN- $\beta$ in bmGMDCs infected with live $B$. abortus relative to bmGM-DCs infected with $S$. typhimurium. These results suggest DC maturation impairment in cells infected with Brucella (Salcedo et al. 2008).

In a comparative study, human monocyte-derived GM-DCs were infected with different intracellular bacterial pathogens: Orientia tsutsugamushi the etiologic agent of scrub typhus, Coxiella burnetii responsible for Q fever, and Brucella. Although these bacterial pathogens have an intracellular lifestyle, they have different preferential niches for their replication; while B. abortus 2308 and C. burnetii reside in an intracellular vacuole, $O$. tsutsugamuchi is located in the cytoplasm (Benoit et al. 2008; Gorvel et al. 2014; Tantibhedhyangkul et al. 2013). Gorvel et al. (2014) infected GM-DCs with B. abortus 2308, C. burnetii, and O. tsutsugamuchi for 24 h. Compared with GM-DCs infected with $C$. burnettii or O. tsutsugamushi, B. abortus-infected GM-DCs showed impaired immune responses. However, the expression of CD83 (a DC maturation marker), and costimulatory molecules (CD80 and CD86) was relatively higher in $O$. tsutsugamushi-infected GM-DCs, than B. abortus 2308- and C. burnetii-infected cells (Gorvel et al. 2014). Despite the intracellular lifestyle of these pathogens, notable differences in GM-DC immune responses were observed; further analysis involving transcriptomics was performed on infected GM-DCs. Transcriptomic analysis revealed high levels of IFN- $\beta$ in GM-DCs infected with $O$. tsutsugamushi, whereas IFN- $\beta$ expression was impaired in 
Brucella- and C. burnetti-infected GM-DCs. According to the results obtained, IFN type I was impaired due to defective activation of $\mathrm{p} 38$ in GM-DCs infected with B. abortus 2308 and C. burnetii (Gorvel et al. 2014).

Compared with human or murine DCs, bovine monocytederived GM-DCs are not permissive for B. abortus proliferation. Heller et al. (2012) found low expression of costimulatory molecules (CD80 and CD86) and cytokines (IL12p40 and IFN $\gamma$ ) in bovine monocyte-derived GM-DCs infected with $B$. abortus, but no bacterial proliferation was observed (Heller et al. 2012). While the proliferation of bacteria in macrophages is commonly observed, intracellular bacterial proliferation in DCs is poor, probably because phagolysosome acidification is decreased in these cells. It is well known that Brucella requires phagolysosome acidification for the expression of crucial virulence factors for intracellular survival (Starr et al. 2008).

\section{Does Brucella truly impair DC activation/maturation?}

It is evident that there are discrepancies between the results reported in the literature regarding $\mathrm{DC}$ activation/maturation, probably due to the DC subsets used in experiments, the species of Brucella or antigens, and the time points used for stimulation/infection, among others.

Billard et al. (2007b) found low activation levels of CD83, costimulatory molecules, and chemokine receptors at $48-\mathrm{h}$ postinfection in human GM-DCs infected with B. suis, whereas Zwerdling et al. (2008) observed high expression levels of surface molecules at early time points (24-h postinfection) in human GM-DCs infected with B. abortus. Likely, the induction of surface molecules reaches its maximum intensity at different time points after infection, explaining why differences were observed between these reports. Moreover, Billard et al. (2007b) performed GMDC differentiation for 5 days, while Zwerdling et al. (2008) did so for 6 days. Additionally, Zwerdling et al. (2008) induced a further maturation step using different antigens (Escherichia coli LPS, B. abortus LPS, HKBa, Pam3Cys, Lipidated-Omp 19, and Unlipidated-Omp19), whereas Billar et al. stimulated the cells after differentiation with cytokines. Despite the impaired GM-DC maturation observed in the experiments of Billard et al., Brucella infection was slightly detected based on the immune response, since low cytokine levels were induced. Based on the observation of Brucella infection in DCs, it can be hypothesized that DC activation mediated by Brucella is present at the onset of the immune response, while at later time points, the pathogen might avert a Th1 response by establishing chronic infection through different host immune system evasion mechanisms (Billard et al. 2007a, 2007b; Zwerdling et al. 2008).
Reports of murine DCs infected with Brucella have presented contrasting information. Macedo et al. (2008) used heat-killed B. abortus 2308 (1000 bacteria/cell) to infect murine DCs, observing upregulation of costimulatory molecules, as well as significant cytokine production. Salcedo and colleagues used living B. abortus 2308 strain (20-50 bacteria/ cell) and observed decreased expression of surface molecules and low cytokine concentrations.

\section{The stealthy nature of Brucella hampers the immune response of $D C$ subsets}

Human and mouse GM-DCs have been the most commonly used model to study Brucella-DC interaction. Since Brucella can disseminate and reach different lymphoid tissues such as the spleen, the bacteria can interact with different DC subsets.

Papadopoulos et al. (2016) demonstrated that Brucella can infect different bone marrow-derived DC subsets. Bone marrow cells were differentiated in GM-DCs, FL-DCs (pDCs, and $\mathrm{CD} 8 \alpha^{+}$, and $\mathrm{CD}_{11} \mathrm{~b}^{+}$equivalent to $\left.\mathrm{cDCs}\right), \mathrm{GM} / \mathrm{FL}-\mathrm{DCs}$ (GM-CSF plus FLT3L DCs), and GM/15-DCs (GM-CFS plus IL-15 DCs) and then infected with virulent $B$. abortus 2308 strain. In the case of GM/FL-DCs, GM-CSF decreased $\mathrm{CD} 8 \alpha^{+}$DCs and pDCs, while CD $11 \mathrm{~b}^{+}$DCs increased these subsets. On the other hand, GM/15-DCs produced higher levels of IFN $\gamma$ and IL-12 (promoting Th1 response) than GM-DCs (Brasel et al. 2000; Naik et al. 2005; Papadopoulos et al. 2016). When DC subsets were infected with Brucella, different infection kinetics were observed; for example, FL-DCs and GM/15-DCs showed higher infection levels at early time points than GM/FL-DC or GM-DCs. Brasel et al. (2000) observed the similar efficiency of FLDCs and GM-DCs for ovalbumin (OVA) uptake; however, Brucella uptake may be mediated by different mechanisms (i.e., lipid rafts and/or phagocytosis). At late times postinfection, Brucella uptake levels were similar in all different DC subsets. On the other hand, GM-DCs and GM/FL-DCs showed late maturation (high levels of CD86, CD80, and MHC-II at $48 \mathrm{~h}$ ), while GM/15-DCs and FL-DCs (only $\mathrm{CD} 8 \alpha^{+}$and $\mathrm{CD} 11 \mathrm{~b}^{+} \mathrm{DCs}$ ) showed early maturation at $24-\mathrm{h}$ postinfection. GM-DCs and GM/FL-DCs induced high levels of IL-10 corresponding to late maturation of cells. FL-DCs and GM/15-DCs showed higher expression of INF $\gamma$, IL-12, IL-6, IFN $\beta$, and IL-1 $\beta$ as well as higher levels of chemokine and chemokine receptor (CCL2 and CCR7) corresponding to early maturation. Moreover, in DC subsets with inflammatory cytokine profiles, Brucella replication was lower than that in GM-DCs and GM/FL-DCs (Papadopoulos et al. 2016).

During Brucella infection, IL-10 production is commonly observed; mouse GM-DCs produce IL-10 at 24-h postinfection and splenocytes from infected mice produced high levels of this cytokine up to 6 weeks postinfection. In this sense, DCs, $\mathrm{CD} 4^{+}$ $\mathrm{T}$ cells, and macrophages from the spleen are the main IL-10 
producers (Corsetti et al. 2013). IL-10 is considered an immunoregulatory cytokine that is able to suppress IL-12 production and modulate an excessive Th1 response (Couper et al. 2008). During Brucella infection, IL-10 production at early times is crucial for evolution to chronic brucellosis, which includes the inhibition of pro-inflammatory cytokines. Xavier et al. (2013) found that at early times during Brucella infection, IL-10 produced by $\mathrm{CD} 4^{+} \mathrm{CD} 25^{+} \mathrm{T}$ cells has a regulatory effect during the acute phase, which decreases inflammation and tissue damage; this immune response protects bacteria from being eliminated. Valuable data were obtained in experiments using IL-10 KO mice infected with $B$. abortus. IL-10 KO mice showed lower bacterial loads than wild-type mice. Additionally, GM-DCs from IL-10 KO mice produced higher levels of proinflammatory cytokines than GM-DCs from wild-type mice. Altogether, these results indicate that IL-10 has a detrimental effect on the protective immune response against Brucella (Couper et al. 2008); Xavier et al. 2013).

The stealthy nature of Brucella is attributed mainly to the smooth LPS on its surface. Typical LPS is composed of lipid $\mathrm{A}$, a core oligosaccharide, and an O-side chain polysaccharide. Brucella LPS is an unbranched homopolymer ranging from 96 to 100 glycosyl subunits; the O-side chain is linked to a core oligosaccharide, and the lipid A is linked to the core oligosaccharide (Cardoso et al. 2006). LPS plays an important role in Brucella pathogenesis, protecting from cellular cationic peptides, reactive oxygen species, and complement-mediated lysis and is involved in invasion. Brucella LPS is less cytotoxic than enterobacterial LPS (Cardoso et al. 2006; von Bargen et al. 2012). There is some controversy as to whether or not Brucella LPS hampers the DC immune response; as mentioned above, some authors have reported DC maturation/activation inhibition by smooth Brucella strains, whereas DCs infected with rough strains showed maturation/ activation and proinflammatory cytokine profiles.

Outer membrane vesicles (OMVs) are nanovesicles released from the outer membrane of Gram-negative bacteria. OMVs contain proteins from the outer membrane, periplasm, and cytoplasm, as well as LPS. These vesicles have been reported in B. melitensis and B. abortus. Purified vesicles from B. melitensis $16 \mathrm{M}$ and the rough mutant $B$. melitensis VTRM1 were used to measure the levels of cytokine expression in murine bmGM-DCs at different time points. The results revealed early expression of IL-12, IFN $\gamma$, and TNF $\alpha$ in bmGM-DCs stimulated with OMVs from $B$. melitensis rough strain but not expression with OMVs from a smooth strain (Avila-Calderón et al. 2012). These differences could be attributed to the O-side chain lacking the LPS of OMVs from the rough strain.

Conde-Álvarez et al. (2012) found a relationship between the core oligosaccharide and immune response impairment in DCs. In their experiments, the authors used the B. abortus wadC mutant; the wadC gene encodes a mannosyltransferase that is important for the assembly of complete LPS. The B. abortus
wadC mutant exhibited a partially defective core oligosaccharide but an intact lipid $\mathrm{A}$ and O-side chain. bmGM-DCs were stimulated with LPS purified from the $w a d C$ mutant and wildtype strain. The mutant LPS induced higher production of IL-12, TNF $\alpha$, and CD86 and MHC-II overexpression, but cells stimulated with the wild-type LPS did not (Conde-Álvarez et al. 2012). Similar experiments were performed by Zhao et al. (2018) using human monocyte-derived GM-DCs stimulated with $B$. melitensis-wadC mutant LPS and wild type LPS, the production of IL-12p70, IL-6, and TNF $\alpha$ was observed only in cells stimulated with mutant LPS (Zhao et al. 2018).

Clearly, immune response impairment in GM-DCs is due to the core oligosaccharide in Brucella LPS, but this is not the rule in all DCs subsets. For example, in the case of FL-DCs stimulated with $B$. melitensis wild-type LPS, the $\mathrm{CD} 11 \mathrm{~b}^{+}$and $\mathrm{CD} 8 \alpha^{+}$, but not $\mathrm{pDC}$, subsets upregulated the expression of CD86, CD80, CD40, and MHC-II molecules and secrete significant amounts of TNF $\alpha$, IL-12p40, IL-6, and IL-10. Additionally, upregulation of surface molecules and cytokine production was observed in FL-DCs DCs stimulated with $B$. melitensiswadC mutant LPS but was higher than that observed in FLDCs stimulated with wild-type LPS. However, despite the activation profiles elicited in $\mathrm{CD} 11 \mathrm{~b}^{+}$and $\mathrm{CD} 8 \alpha^{+}$cells stimulated with wild-type LPS, these DCs were not able to induce the proliferation of $\mathrm{CD}^{+}$or $\mathrm{CD} 4^{+} \mathrm{T}$ cells (Zhao et al. 2018).

It has been reported that human or mouse GM-DCs treated with $B$. abortus or pure wild-type LPS hampered proinflammatory cytokine profiles and demonstrated an inability to upregulate costimulatory molecules (Conde-Álvarez et al. 2012; Papadopoulos et al. 2016). Papadopoulos et al. observed maturation at 48-h postinfection and high production of IL-10 in murine GM-DCs infected with $B$. abortus 2308. Conde-Álvarez et al. (2012) did not observe costimulatory molecule expression in murine GM-DCs after $72 \mathrm{~h}$ of stimulation with $B$. abortus wild-type LPS. In addition, in both studies, upregulation of surface molecules and induction of a Th1 cytokine profile in

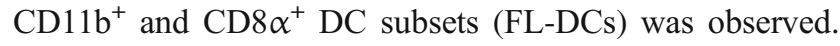
Papadopoulos et al. observed IFN $\gamma$ secretion at 24-h postinfection and late upregulation of IL-10 production $(48 \mathrm{~h}$ ) when DCs were infected with whole $B$. abortus 2308. Late IL-10 induction potentially counteracts IFN $\gamma$ effects and impairs DC response (Conde-Álvarez et al. 2012; Papadopoulos et al. 2016).

\section{Molecular interaction: how does Brucella avoid DCs immune response?}

\section{Brucella spp., are recognized by TLRs from DC subsets and activate intracellular pathways for cytokine production}

TLRs are involved in recognizing pathogen-associated molecular patterns (PAMPs), and in some cases, DC activation is 
initiated by these receptors. TLRs have an extracellular leucine-rich repeat (LRR) domain, and the intracytoplasmic domain Toll/IL-1 receptor domain (TIR domain) homologous to the IL-1 receptor family (IL-1R) is crucial for intracellular signaling. Myeloid differentiation factor 88 (MyD88) is an adaptor protein which possesses a TIR domain and associates with IL-1R family members including TLRs (Kaisho and Akira 2001).

Based on their observations, Zwerdling et al. (2008) proposed that Brucella signals through TLR2, since GM-DCs stimulated with pure Brucella Omp19 impaired cytokine production when this receptor was blocked. On the other hand, Huang et al. (2005) observed a prominent role for TLR9 and MyD88 in CD11 ${ }^{+}$DCs isolated from the spleen for IL-12 production after the cells were treated with HKBa (Huang et al. 2005; Zwerdling et al. 2008). TLR2 and TLR4 are superficial receptors at the cytoplasmic membrane and are recruited at the site of the pathogen interaction during phagocytosis, whereas TLR9 is an intracellular receptor that recognizes distinct patterns of nucleic acids in endosomes (Kaisho and Akira 2001).

Zhang et al. (2012) observed that TLR2, but not TLR4 is required for $\mathrm{HKBa}$ phagocytosis in $\mathrm{CD} 8 \alpha^{-}$and $\mathrm{CD} 8 \alpha^{+} \mathrm{DCs}$ isolated from mouse spleen. HKBa phagocytosis induced the production of TNF $\alpha$ and IL-12; TLR2 was important for TNF $\alpha$ production, while TLR9 was related to IL-12 production and was MyD88 signaling-dependent. However, TLR4 was not required for the production of any cytokines in both DC spleen subsets. Additionally, it was demonstrated that TLR2-TLR9 cooperation was necessary for the production of pro-inflammatory cytokines. HKBa interacts with TLR2 in splenic DCs and signals through p38, leading to phagocytosis, and signals for TNF $\alpha$ production, resulting in phagolysosome fusion; then TLR9 interacts with bacterial DNA in late endosomes, signaling for IL-12 production (Zhang et al. 2012). On the other hand, in bmGM-DCs infected with $B$. abortus, TLR6 expression was higher than TLR2 expression, and TLR6 was found to be more important for IL12 and TNF $\alpha$ production (de Almeida et al. 2013).

To identify the differential roles of TLRs in Brucella elimination in a pulmonary infection model, bmGM-DCs from TLR2, TLR4, and TLR9 KO mice were infected with rough vaccine $B$. abortus RB51 and smooth virulent $B$. abortus 2308. bmGM-DCs infected with strain RB51 showed higher levels of MHC-II, CD40, and CD86 expression mediated by TLR2, 4, and 9, as well as IL-12 production mediated by TLR2 and TLR4, than the smooth virulent strain. GM-DCs from wild-type mice showed impaired activation. DC activation was induced using MOI $=100$ in the case of B. abortus 2308 , while $\mathrm{MOI}=10$ was necessary in the case of the rough strain to activate cells (Surendran et al. 2012).

Clearly, IL-12 production is necessary for an appropriate Th1 response against brucellosis. TLR4 is the only receptor that signals through both TRIF (TIR-domain-containing adapter-inducing interferon- $\beta$ ) and MyD88 upon stimulation and acts synergistically in DCs for IL-12 production (Krummen et al. 2010). In this sense, Zhang et al. (2012) demonstrated IL-12 production-independent TLR4 signaling by splenic DCs infected with $B$. abortus; however, Surendran et al. (2012) proposed TLR4 participation in IL-12 production during $B$. abortus infection.

Recently, TLR3 and TLR7 have been implicated in sensing Brucella RNA. B. abortus RNA-induced IL-6, IL-12, and $\mathrm{TNF} \alpha$ production in murine bmGC-DCs; this cytokine production was TLR-dependent and occurred via MAPK/NF- $K B$ signaling. Although TLRs were required to sense bacterial RNA and cytokine production, they were not necessary for Brucella eradication in vivo (Campos et al. 2017).

Almost all TLRs signal through MyD88, but alternative downstream signaling pathways could be involved in cytokine production. For example, Zhang et al. (2012) observed TNF $\alpha$ production mediated by TLR 2 via $\mathrm{p} 38$ activation. On the other hand, TLR2 also activates ERK1/2 and exerts negative feedback for IL-12 production mediated by TLR9.

Upon activation, TLRs signal through the common adaptor molecule MyD88 (except TLR3) and recruit interleukin-1 (IL1) receptor-associated kinase (IRAK) and tumor necrosis factor (TNF) receptor-associated factor 6 (TRAF6). Once TLRs interact with MyD88, IRAK is activated by TAK1 (transforming growth factor-activated kinase) in a phosphorylation-dependent manner. Activated IRAK associates with TRAF6, leading to the activation of JNK (Janus kinase) and culminating in I $\kappa B$ degradation and NF- $k B$ translocation to the nucleus for the transcription of proinflammatory cytokine genes such as IL-12 and TNF $\alpha$ (Kawai and Akira 2007; Takeda and Akira 2015; Underhill and Ozinsky 2002).

Additionally, IRAK-4 was found to be involved in the production of IL-12 and TNF $\alpha$ in macrophages and DCs infected by Brucella. Bone marrow-derived macrophages and bmGMDCs from IRAK $-4^{-/}$mice were stimulated with live $B$. abortus 2308, HKBa, TLR2, and TLR9 agonists, IRAK-4 deficient macrophages and bmGM-DCs showed impaired production of TNF $\alpha$ and IL-12, demonstrating an essential role for IRAK-4 in the production of pro-inflammatory cytokines upon Brucella recognition by TLRs (Oliveira et al. 2011).

\section{Brucella TIR proteins and other virulence factors act as immune modulators of DCs}

A more detailed study of the interaction of mouse GM-DCs and B. abortus 2308 was performed using microarrays. Functional expression analysis showed that not only type I IFN response but also MAPK p38 activation were impaired (Gorvel et al. 2014). It has been reported that the O-side chains of LPS from B. melitensis $16 \mathrm{M}$, B. abortus 2308 , and B. suis 1330 are able 
to restrict the activation of $\mathrm{p} 38$ in murine J774A.1 macrophages. Additionally, the production of inflammatory cytokines and chemokines depends on p38 MAPKs (Jiménez de Bagüés et al. 2005). Taking into account these data, we can show that Brucella modulates DC maturation by impairing the type I IFN and the immune response, allowing bacterial intracellular persistence and chronic infection.

Another strategy used by Brucella to avoid the host immune response involves blocking or impairing TLRs signaling pathway through bacterial TIR homologs (Rana et al. 2013). Cirl et al. identified bacterial TIR-domain proteins in uropathogenic E. coli CFT073 and Brucella species, referred as TIR-domain-containing proteins $\mathrm{C}(\mathrm{TcpC})$ and $\mathrm{B}(\mathrm{TcpB}$, also known as BtpA), respectively (Cirl et al. 2008). The $b t p A$ gene was found in B. melitensis and B. abortus, but not in the $B$. suis genome; the genetic evidence proposes that these genes were acquired recently via a phage-mediated integration event. The BtpA protein interferes with NF- $\mathrm{kB}$ activation mediated by TLR4 and TLR2 signaling, as well as cytokine production and DC maturation (Radhakrishnan et al. 2009).

For TLRs, activation adaptor proteins are recruited, one of which is Toll-interleukin-1 receptor domain-containing adaptor protein (TIRAP, also known as MAL; MyD88 adaptor protein). TIRAP is an adaptor molecule for the MyD88dependent pathway derived from TLR2 and TLR4-signaling (Kawai and Akira 2007; Underhill and Ozinsky 2002). Radhakrishnan et al. (2009) observed no interaction between BtpA, TLR2, TLR4, or TIRAP to inhibit NF-kB activation in HEK293 cells transfected with the $b t p A$ gene. Interestingly, BtpA was found to mimic TIRAP function during TLRs signaling; BtpA likely competes with MyD88 and blocks downstream signaling (Radhakrishnan et al. 2009). On the other hand, recombinant BtpA was able to induce the degradation of TIRAP, while other TLR components were not affected. It has been suggested that the interaction of BtpA and TIRAP facilitates the ubiquitination of TIRAP for its degradation (Fig. 1) (Sengupta et al. 2010).

MyD88 possesses an amino-terminal death domain (DD) involved in cell death and signaling. Through the interaction of their DDs, MyD88 recruits the IRAK-1 and IRAK-4 kinases (Loiarro et al. 2009). According to a fragment complementation assay, it was possible to determine that BtpA interacts directly with MyD88 and TIRAP through the DDs. The interaction between BtpA and MyD88 was stronger than that observed with BtpA-TIRAP. Although BtpA interacts strongly with MyD88, the interaction does not impair downstream signaling (Fig. 1) (Chaudhary et al. 2012).

A second TIR-domain-containing protein (BAB1_0756) in the Brucella genome was discovered and designated as BtpB. BtpB is a potent inhibitor of TLR2, TLR4, TLR5 and TLR9 signaling. Infection of murine bmGM-DCs with $B$. abortus BtpB mutant led to the reduction of TNF $\alpha$ and IL-12. Some differences were observed between BtpA and BtpB; for example, BtpA, but not BtpB impaired TNF $\alpha$ production, while BtpB decreased the expression of MHC-II, CD40, CD86, and CD80 in bmGM-DC cells. However, both proteins contributed to the control of DC activation during Brucella infection (Salcedo et al. 2013). Based on this evidence, BtpA may affect TIRAP functions but could also interact directly with MyD88 in a DD-domain dependent manner, although not with the TIR domain. BtpB also showed stronger MyD88-binding and likely blocks TLRs that are dependent on MyD88 signaling (Fig. 1) (Salcedo et al. 2013).

\section{Concluding remarks}

Brucella invades and replicates in a variety of host cells. A high percentage of the studies to examine Brucella pathogenesis, host-pathogen interaction, virulence, etc., are performed in macrophages, and in some cases, these cells are the preferential niche for intracellular replication. However, there is no doubt that DCs are an intracellular niche for Brucella species, and their migratory properties allow bacterial dissemination. With the exception of bovine-derived DCs, this pathogen infects and replicates inside DCs. Brucella recognition at the outside of the eukaryotic cell is mediated by TLRs and signaling triggers the immune response, as shown by cytokine production. Despite discrepancies regarding DC activation/ maturation after Brucella infection, it is clear that Brucella infection is detected by murine or human GM-DCs since the bacteria drive low pro-inflammatory cytokine levels. Unlike other intracellular pathogens such as Salmonella, which induces high levels of pro-inflammatory cytokines and the expression of activation/maturation surface molecules, Brucella is able to subvert or "delay" the DC response, impairing the inflammatory response or the expression of surface molecules. At later times postinfection, Brucella exerts immunomodulatory mechanisms to avoid a protective immune response, promoting intracellular trafficking and reaching its intracellular niche by blocking TLR signaling and cytokine production.

It is evident that there is a controversy regarding whether infection with Brucella prevents or promotes the activation/ maturation of DCs. In part, this contradiction is due to a large number of variables that are managed in experiments using DCs, for example, the bacterial strains used, the bacterial dose and the time for infection/stimulation. It is impossible to homogenize all methodologies, since one DC subset cannot be used because, as we have emphasized in this review, there are several DC phenotypes. On the other hand, the genetic variation of Brucella strains, even though the same bacterial species are used, including references or clinical isolated strains, may affect the results. Similarly, it is impossible to control the physiological and genetic variations of the animals and donors used to obtain DCs. Undeniably, the nature of the stimulus used causes variations in the results, since stimulation 


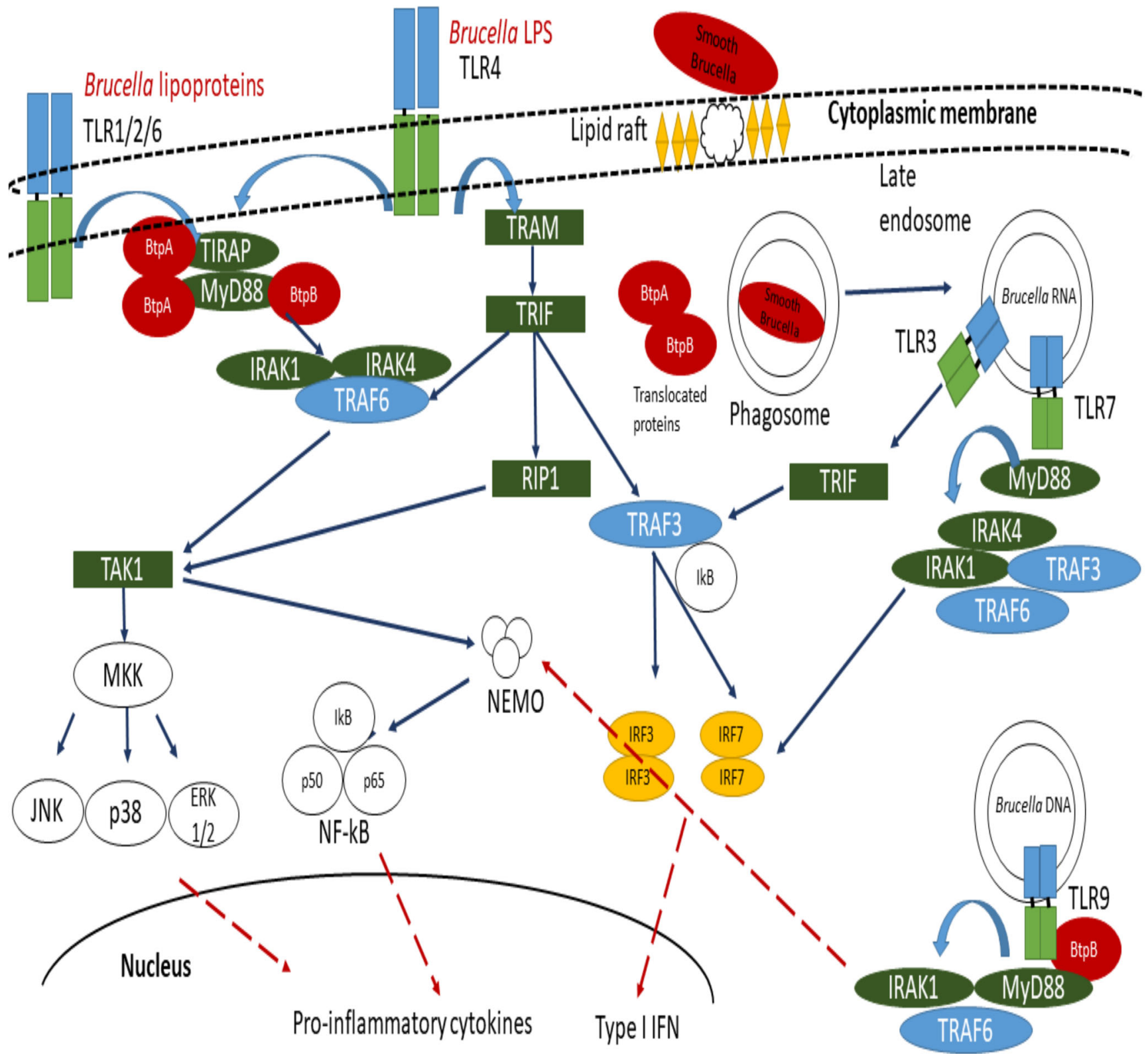

Fig. 1 Schematic representation of Brucella-DC interaction. Lipid raftsmediated interaction between Brucella and DCs has been reported. TLR2, TLR4, TLR6, TLR3, TLR7, and TLR9 have been involved in Brucella recognition. However, Brucella phagocytosis involved recruitment of TLR2 but not TLR4 at the cytoplasmic membrane, and almost $90 \%$ of the ingested Brucella are eliminated by professional phagocytes; the fusion of late endosomes with intracellular receptors such as TLR9 allows type I IFN induction. Once inside, Brucella survive inside phagocytic vacuole and evade late endosomal traffic to reach intracellular niche.
Brucella TIR proteins are translocated into cytoplasmic compartment. BtpA impairs DC activation/maturation through MyD88 and TIRAP interaction (Chaudhary et al. 2012; Radhakrishnan et al. 2009; Sengupta et al. 2010), and BtpB binds to various eukaryotic TIR-proteins (TLR2, TLR4, TLR9 MyD88, TIRAP, etc.) (Salcedo et al. 2013). Moreover, Brucella impairs type I Interferon family expression. Blue solid arrows indicate intracellular pathways activated via Brucella recognition by TLRs. Red dashed arrows indicate impaired cytokine pathways by Brucella TIR proteins and subsequent DCs maturation performed with a purified protein, purified LPS, heat-killed bacteria or a live mutant strain is not the same. For example, in the case of subunit stimuli, although they are fundamentally important to determine the role of a specific macromolecule, they do not contain all elements encompassed by the whole bacterium and act together at the time of infection. However, some variables can be controlled, such as the dose and time of infection/stimulation with Brucella or Brucella antigens, the time of DC subset differentiation, the strain and the age of the animals used.

Thanks to studies of the interaction between Brucella and DCs, it has been possible to identify important virulence factors that may be key therapeutic targets for the control of brucellosis, for example, the proteins BtpA and BtpB, the core 
region of LPS or the wadC gene. These elements fundamentally affect the immune response induced by dendritic cells.

Acknowledgments The authors thank SM Boyle for editing and provide suggestions on the manuscript.

Funding information This work was funded by CONACYT CB-201101 No. 169259, SIP-IPN 20182152, and ICYT-DF/IPN. ACR was supported by fellowships from COFAA-IPN, SIP-EDI, and SNICONACYT.

\section{Compliance with ethical standards}

Conflict of interest The authors declare that they have no conflict of interest.

Publisher's note Springer Nature remains neutral with regard to jurisdictional claims in published maps and institutional affiliations.

\section{References}

Ahmed W, Zheng K, Liu ZF (2016) Establishment of chronic infection: Brucella's stealth strategy. Front Cell Infect Microbiol 6:30. https:// doi.org/10.3389/fcimb.2016.00030

Archambaud C, Salcedo SP, Lelouard H, Devilard E, de Bovis B, Van Rooijen N, Gorvel JP, Malissen B (2010) Contrasting roles of macrophages and dendritic cells in controlling initial pulmonary Brucella infection. Eur J Immunol 40(12):3458-3471. https://doi. org/10.1002/eji.201040497

Avila-Calderón ED, Lopez-Merino A, Jain N, Peralta H, López-Villegas EO, Sriranganathan N, Boyle SM, Witonsky S, ContrerasRodríguez A (2012) Characterization of outer membrane vesicles from Brucella melitensis and protection induced in mice. Clin Dev Immunol 2012:352493. https://doi.org/10.1155/2012/352493

Baldwin CL, Goenka R (2006) Host immune responses to the intracellular bacteria Brucella: does the bacteria instruct the host to facilitate chronic infection? Crit Rev Immunol 26(5):407-442. https://doi. org/10.1615/CritRevImmunol.v26.i5.30

Banchereau J, Steinman RM (1998) Dendritic cells and the control of immunity. Nature 392:245-252. https://doi.org/10.1038/32588

Barquero-Calvo E, Chaves-Olarte E, Weiss DS, Guzmán-Verri C, Chacón-Díaz C, Rucavado A, Moriyón I, Moreno E (2007) Brucella abortus uses a stealthy strategy to avoid activation of the innate immune system during the onset of infection. PLoS One 2(7): e631. https://doi.org/10.1371/journal.pone.0000631

Benoit M, Barbarat B, Bernard A, Olive D, Mege JL (2008) Coxiella burnetii, the agent of $\mathrm{Q}$ fever, stimulates an atypical M2 activation program in human macrophages. Eur J Immunol 38(4):1065-1070. https://doi.org/10.1002/eji.200738067

Billard E, Dornand J, Gross A (2007a) Interaction of Brucella suis and Brucella abortus rough strains with human dendritic cells. Infect Immun 75:5916-5923. https://doi.org/10.1128/IAI.00931-07

Billard E, Dornand J, Gross A (2007b) Brucella suis prevents human dendritic cell maturation and antigen presentation through regulation of tumor necrosis factor alpha secretion. Infect Immun 75(10):4980 4989. https://doi.org/10.1128/IAI.00637-07

Blasco JM (1997) A review of the use of B. melitensis Rev 1 vaccine in adult sheep and goats. Prev Vet Med 31:275-283

Brasel K, De Smedt T, Smith JL, Maliszewski CR (2000) Generation of murine dendritic cells from flt3-ligand-supplemented bone marrow cultures. Blood 96(9):3029-3039
Bystrom J, Taher TE, Muhyaddin MS, Clanchy FI, Mangat P, Jawad AS, Williams RO, Mageed RA (2015) Harnessing the therapeutic potential of Th17 cells. Mediat Inflamm 2015:205156. https://doi.org/10. $1155 / 2015 / 205156$

Campos PC, Gomes MT, Guimarães ES, Guimarães G, Oliveira SC (2017) TLR7 and TLR3 sense Brucella abortus RNA to induce proinflammatory cytokine production but they are dispensable for host control of infection. Front Immunol 8:28. https://doi.org/10. 3389/fimmu.2017.00028

Cardoso PG, Macedo GC, Azevedo V, Oliveira SC (2006) Brucella spp. noncanonical LPS: structure, biosynthesis, and interaction with host immune system. Microb Cell Factories 5(13):13. https://doi.org/10. 1186/1475-2859-5-13

Carpenter CM (1924) Bacterium abortem invasion of the tissues of calves from the ingestion of infected milk. Cornell Vet 14:16-31

Castañeda-Roldán EI, Ouahrani-Bettache S, Saldaña Z, Avelino F, Rendón MA, Dornand J, Girón JA (2006) Characterization of SP41, a surface protein of Brucella associated with adherence and invasion of host epithelial cells. Cell Microbiol 8(12):1877-1887. https://doi.org/10.1111/j.1462-5822.2006.00754.x

Chaudhary A, Ganguly K, Cabantous S, Waldo GS, Micheva-Viteva SN, Nag K, Hlavacek WS, Tung CS (2012) The Brucella TIR-like protein TcpB interacts with the death domain of MyD88. Biochem Biophys Res Commun 417(1):299-304. https://doi.org/10.1016/j. bbrc.2011.11.104

Cheville NF, Kunkle RA, Jensen AE, Palmer MV (1995) Persistence of Brucella abortus in the livers of T cell-deficient nude mice. Lab Investig 73(1):96-102

Cirl C, Wieser A, Yadav M, Duerr S, Schubert S, Fischer H, Stappert D, Wantia N, Rodriguez N, Wagner H, Svanborg C, Miethke T (2008) Subversion of Toll-like receptor signaling by a unique family of bacterial Toll/interleukin-1 receptor domain-containing proteins. Nat Med 14(4):399-406. https://doi.org/10.1038/nm1734

Colonna M, Pulendran B, Iwasaki A (2006) Dendritic cells at the hostpathogen interface. Nat Immunol 7(2):117-120. https://doi.org/10. 1038/ni0206-117

Conde-Álvarez R, Arce-Gorvel V, Iriarte M, Manček-Keber M, Barquero-Calvo E, Palacios-Chaves L, Chacón-Díaz C, ChavesOlarte E, Martirosyan A, von Bargen K, Grilló MJ, Jerala R, Brandenburg K, Llobet E, Bengoechea JA, Moreno E, Moriyón I, Gorvel JP, Renée MT (2012) The lipopolysaccharide core of Brucella abortus acts as a shield against innate immunity recognition. PLoS Pathog 8(5):e1002675. https://doi.org/10.1371/journal. ppat. 1002675

Corsetti PP, de Almeida LA, Carvalho NB, Azevedo V, Silva TM, Teixeira HC, Faria AC, Oliveira SC (2013) Lack of endogenous IL-10 enhances production of proinflammatory cytokines and leads to Brucella abortus clearance in mice. PLoS One 8(9):e74729. https://doi.org/10.1371/journal.pone.0074729

Couper KN, Blount DG, Riley EM (2008) IL-10: the master regulator of immunity to infection. J Immunol 180(9):5771-5777. https://doi. org/10.4049/jimmunol.180.9.5771

Czibener C, Ugalde JE (2012) Identification of a unique gene cluster of Brucella spp. that mediates adhesion to host cells. Microbes Infect 14(1):79-85. https://doi.org/10.1016/j.micinf.2011.08.012

de Almeida LA, Macedo GC, Marinho FA, Gomes MT, Corsetti PP, Silva AM, Cassataro J, Giambartolomei GH, Oliveira SC (2013) Toll-like receptor 6 plays an important role in host innate resistance to Brucella abortus infection in mice. Infect Immun 81(5):16541662. https://doi.org/10.1128/IAI.01356-12

de Figueiredo P, Ficht TA, Rice-Ficht A, Rossetti CA, Adams LG (2015) Pathogenesis and immunobiology of brucellosis: review of Brucella-host interactions. Am J Pathol 185(6):1505-1517. https:// doi.org/10.1016/j.ajpath.2015.03.003

Dean AS, Crump L, Greter H, Hattendorf J, Schelling E, Zinsstag J (2012) Clinical manifestations of human brucellosis: a systematic 
review and meta-analysis. PLoS Negl Trop Dis 6(12):e1929. https:// doi.org/10.1371/journal.pntd.0001929

del Rio ML, Bernhardt G, Rodriguez-Barbosa JI, Förster R (2010) Development and functional specialization of $\mathrm{CD}_{103^{+}}$dendritic cells. Immunol Rev 234(1):268-281. https://doi.org/10.1111/j. 0105-2896.2009.00874.x

Elfaki MG, Al-Hokail AA (2009) Transforming growth factor beta production correlates with depressed lymphocytes function in humans with chronic brucellosis. Microbes Infect 11(14-15):1089-1096. https://doi.org/10.1016/j.micinf.2009.08.001

Elfaki MG, Alaidan AA, Al-Hokail AA (2015) Host response to Brucella infection: review and future perspective. J Infect Dev Ctries 9(7): 697-701. https://doi.org/10.3855/jidc.6625

Enright FM, Araya LN, Elzer PH, Rowe GE, Winter AJ (1990) Comparative histopathology in $\mathrm{BALB} / \mathrm{c}$ mice infected with virulent and attenuated strains of Brucella abortus. Vet Immunol Immunopathol 26(2):171-182

Fabrik I, Härtlova A, Rehulka P, Stulik J (2013) Serving the new mastersdendritic cells as hosts for stealth intracellular bacteria. Cell Microbiol 15(9):1473-1483. https://doi.org/10.1111/cmi.12160

Giambartolomei GH, Arriola Benitez PC, Delpino MV (2017) Brucella and osteoarticular cell activation: partners in crime. Front Microbiol 8:256. https://doi.org/10.3389/fmicb.2017.00256

Goenka R, Guirnalda PD, Black SJ, Baldwin CL (2012) B lymphocytes provide an infection niche for intracellular bacterium Brucella abortus. J Infect Dis 206(1):91-98. https://doi.org/10.1093/infdis/ jis310

Gorvel JP, Moreno E, Moriyón I (2009) Is Brucella an enteric pathogen? Nat Rev Microbiol 7(3):250; author reply 250. https://doi.org/10. 1038/nrmicro2012-c1

Gorvel L, Textoris J, Banchereau R, Ben Amara A, Tantibhedhyangkul W, von Bargen K, Ka MB, Capo C, Ghigo E, Gorvel JP, Mege JL (2014) Intracellular bacteria interfere with dendritic cell functions: role of the type I interferon pathway. PLoS One 9(6):e99420. https:// doi.org/10.1371/journal.pone.0099420

Grilló MJ, Blasco JM, Gorvel JP, Moriyón I, Moreno E (2012) What have we learned from brucellosis in the mouse model? Vet Res 43:29. https://doi.org/10.1186/1297-9716-43-29

Guilliams M, Ginhoux F, Jakubzick C, Naik SH, Onai N, Schraml BU, Segura E, Tussiwand R, Yona S (2014) Dendritic cells, monocytes and macrophages: a unified nomenclature based on ontogeny. Nat Rev Immunol 14(8):571-578. https://doi.org/10.1038/nri3712

Guzmán-Hernández RL, Contreras-Rodríguez A, Ávila-Calderón ED, Morales-García MR (2016) Brucellosis: a zoonosis of importance in Mexico. Rev Chil Infectol 33(6):656-662. https://doi.org/10. 4067/S0716-10182016000600007

Hanot Mambres D, Machelart A, Vanderwinden JM, De Trez C, Ryffel B, Letesson JJ, Muraille E (2015) In situ characterization of splenic Brucella melitensis reservoir cells during the chronic phase of infection in susceptible mice. PLoS One 10(9):e0137835. https://doi.org/ 10.1371/journal.pone.0137835

Heller MC, Watson JL, Blanchard MT, Jackson KA, Stott JL, Tsolis RM (2012) Characterization of Brucella abortus infection of bovine monocyte-derived dendritic cells. Vet Immunol Immunopathol 149(3-4):255-261. https://doi.org/10.1016/j.vetimm.2012.07.006

Hernández-Castro R, Verdugo-Rodríguez A, Puente JL, Suárez-Güemes $\mathrm{F}$ (2008) The BMEI0216 gene of Brucella melitensis is required for internalization in HeLa cells. Microb Pathog 44(1):28-33. https:// doi.org/10.1016/j.micpath.2007.08.008

Hey YY, O'Neill HC (2012) Murine spleen contains a diversity of myeloid and dendritic cells distinct in antigen presenting function. J Cell Mol Med 16(11):2611-2619. https://doi.org/10.1111/j.1582-4934. 2012.01608.x

Hochrein H, O'Keeffe M, Luft T, Vandenabeele S, Grumont RJ, Maraskovsky E, Shortman K (2000) Interleukin (IL)-4 is a major regulatory cytokine governing bioactive IL-12 production by mouse and human dendritic cells. J Exp Med 192(6):823-833. https://doi. org/10.1084/jem.192.6.823

Huang LY, Ishii KJ, Akira S, Aliberti J, Golding B (2005) Th1-like cytokine induction by heat-killed Brucella abortus is dependent on triggering of TLR9. J Immunol 175(6):3964-3970. https://doi.org/ 10.4049/jimmunol.175.6.3964

Iannino F, Ugalde JE, Iñón de Iannino N (2012) Brucella abortus efp gene is required for an efficient internalization in HeLa cells. Microb Pathog 52(1):31-40. https://doi.org/10.1016/j.micpath.2011.09.008

Itano AA, McSorley SJ, Reinhardt RL, Ehst BD, Ingulli E, Rudensky AY, Jenkins MK (2003) Distinct dendritic cell populations sequentially present antigen to $\mathrm{CD}^{+}{ }^{+} \mathrm{T}$ cells and stimulate different aspects of cell-mediated immunity. Immunity 19(1):47-57. https://doi.org/10. 1016/S1074-7613(03)00175-4

Janeway CA, Medzhitov R (2002) Innate immune recognition. Annu Rev Immunol 20:197-216. https://doi.org/10.1146/annurev.immunol. 20.083001 .084359

Jiménez de Bagüés MP, Gross A, Terraza A, Dornand J (2005) Regulation of the mitogen-activated protein kinases by Brucella spp. expressing a smooth and rough phenotype: relationship to pathogen invasiveness. Infect Immun 73(5):3178-3183. https://doi.org/ 10.1128/IAI.73.5.3178-3183.2005

Jubier-Maurin V, Boigegrain RA, Cloeckaert A, Gross A, AlvarezMartinez MT, Terraza A, Liautard J, Kohler S, Rouot B, Dornand J, Liautard JP (2001) Major outer membrane protein Omp25 of Brucella suis is involved in inhibition of tumor necrosis factor alpha production during infection of human macrophages. Infect Immun 69(8):4823-4830. https://doi.org/10.1128/IAI.69.8.4823-4830. 2001

Kaisho T, Akira S (2001) Dendritic-cell function in Toll-like receptor- and MyD88-knockout mice. Trends Immunol 22(2):78-83. https://doi. org/10.1016/S1471-4906(00)01811-1

Kawai T, Akira S (2007) TLR signaling. Semin Immunol 19(1):24-32. https://doi.org/10.1016/j.smim.2006.12.004

Knickelbein JE, Watkins SC, McMenamin PG, Hendricks RL (2009) Stratification of antigen-presenting cells within the normal cornea. Ophthalmol Eye Dis 1:45-54

Knickelbein JE, Buela KA, Hendricks RL (2014) Antigen-presenting cells are stratified within normal human corneas and are rapidly mobilized during ex vivo viral infection human corneal antigenpresenting cells. Invest Ophthalmol Vis Sci 55(2):1118-1123. https://doi.org/10.1167/iovs. 13-13523

Krummen M, Balkow S, Shen L, Heinz S, Loquai C, Probst HC, Grabbe S (2010) Release of IL-12 by dendritic cells activated by TLR ligation is dependent on MyD88 signaling, whereas TRIF signaling is indispensable for TLR synergy. J Leukoc Biol 88(1):189-199. https://doi.org/10.1189/jlb.0408228

Lelouard H, Henri S, De Bovis B, Mugnier B, Chollat-Namy A, Malissen B, Méresse S, Gorvel JP (2010) Pathogenic bacteria and dead cells are internalized by a unique subset of Peyer's patch dendritic cells that express lysozyme. Gastroenterology 138(1):173-184. https:// doi.org/10.1053/j.gastro.2009.09.051

Lelouard H, Fallet M, de Bovis B, Méresse S, Gorvel JP (2012) Peyer's patch dendritic cells sample antigens by extending dendrites through M cell-specific transcellular pores. Gastroenterology 142(3):592601. https://doi.org/10.1053/j.gastro.2011.11.039

Loiarro M, Gallo G, Fantò N, De Santis R, Carminati P, Ruggiero V, Sette C (2009) Identification of critical residues of the MyD88 death domain involved in the recruitment of downstream kinases. J Biol Chem 284(41):28093-28103. https://doi.org/10.1074/jbc.M109. 004465

Luo X, Zhang X, Wu X, Yang X, Han C, Wang Z, Du Q, Zhao X, Liu SL, Tong D, Huang Y (2018) Brucella downregulates tumor necrosis factor- $\alpha$ to promote intracellular survival via Omp25 regulation of different microRNAs in porcine and murine macrophages. Front Immunol 8:2013. https://doi.org/10.3389/fimmu.2017.02013 
Lyadova IV, Panteleev AV (2015) Th1 and Th17 cells in tuberculosis: protection, pathology, and biomarkers. Mediat Inflamm 2015(854507):1-13. https://doi.org/10.1155/2015/854507

Macedo GC, Magnani DM, Carvalho NB, Bruna-Romero O, Gazzinelli RT, Oliveira SC (2008) Central role of MyD88-dependent dendritic cell maturation and proinflammatory cytokine production to control Brucella abortus infection. J Immunol 180(2):1080-1087. https:// doi.org/10.4049/jimmunol.180.2.1080

Mantegazza AR, Magalhaes JG, Amigorena S, Marks MS (2013) Presentation of phagocytosed antigens by MHC class I and II. Traffic 14(2):135-152. https://doi.org/10.1111/tra.12026

Marzetti S, Carranza C, Roncallo M, Escobar GI, Lucero NE (2013) Recent trends in human Brucella canis infection. Comp Immunol Microbiol Infect Dis 36(1):55-61. https://doi.org/10.1016/j.cimid. 2012.09.002

Murphy EA, Parent M, Sathiyaseelan J, Jiang X, Baldwin CL (2001) Immune control of Brucella abortus 2308 infections in BALB/c mice. FEMS Immunol Med Microbiol 32(1):85-88. https://doi. org/10.1111/j.1574-695X.2001.tb00536.x

Naik SH, Proietto AI, Wilson NS, Dakic A, Schnorrer P, Fuchsberger M, Lahoud MH, O'Keeffe M, Shao QX, Chen WF, Villadangos JA, Shortman K, Wu L (2005) Cutting edge: generation of splenic $\mathrm{CD}^{+}$and CD8- dendritic cell equivalents in Fms-like tyrosine kinase 3 ligand bone marrow cultures. J Immunol 174(11):65926597. https://doi.org/10.4049/jimmunol.174.11.6592

Oliveira FS, Carvalho NB, Brandão AP, Gomes MT, de Almeida LA, Oliveira SC (2011) Interleukin-1 receptor-associated kinase 4 is essential for initial host control of Brucella abortus infection. Infect Immun 79(11):4688-4695. https://doi.org/10.1128/IAI.05289-11

Papadopoulos A, Gagnaire A, Degos C, de Chastellier C, Gorvel JP (2016) Brucella discriminates between mouse dendritic cell subsets upon in vitro infection. Virulence 7(1):33-44. https://doi.org/10. $1080 / 21505594.2015 .1108516$

Pappas G (2010) The changing Brucella ecology: novel reservoirs, new threats. Int J Antimicrob Agents 36(1):S8-S11. https://doi.org/10. 1016/j.ijantimicag.2010.06.013

Pappas G, Papadimitriou P, Akritidis N, Christou L, Tsianos EV (2006) The new global map of human brucellosis. Lancet Infect Dis 6(2): 91-99. https://doi.org/10.1016/S1473-3099(06)70382-6

Poltorak MP, Schraml BU (2015) Fate mapping of dendritic cells. Front Immunol 6:199. https://doi.org/10.3389/fimmu.2015.00199

Pujol M, Castillo F, Alvarez C, Rojas C, Borie C, Ferreira A, Vernal R (2017) Variability in the response of canine and human dendritic cells stimulated with Brucella canis. Vet Res 48(1):72. https://doi. org/10.1186/s13567-017-0476-8

Pulendran B (2004) Modulating Th1/Th2 responses with microbes, dendritic cells, and pathogen recognition receptors. Immunol Res 29(13):187-196. https://doi.org/10.1385/IR:29:1-3:187

Pulendran B, Ahmed R (2011) Immunological mechanisms of vaccination. Nat Immunol 12(6):509-517. https://doi.org/10.1038/ni.2039

Pulendran B, Smith JL, Caspary G, Brasel K, Pettit D, Maraskovsky E, Maliszewski CR (1999) Distinct dendritic cells subsets differentially regulate the class of immune response in vivo. Proc Natl Acad Sci 96:1036-1041. https://doi.org/10.1073/pnas.96.3.1036

Pulendran B, Palucka K, Banchereau J (2001) Sensing pathogens and tuning immune responses. Science 293(5528):253-256. https://doi. org/10.1126/science. 1062060

Radhakrishnan GK, Yu Q, Harms JS, Splitter GA (2009) Brucella TIR domain-containing protein mimics properties of the Toll-like receptor adaptor protein TIRAP. J Biol Chem 284(15):9892-9898. https:// doi.org/10.1074/jbc.M805458200

Rana RR, Zhang M, Spear AM, Atkins HS, Byrne B (2013) Bacterial TIR-containing proteins and host innate immune system evasion. Med Microbiol Immunol 202(1):1-10. https://doi.org/10.1007/ s00430-012-0253-2
Rossetti CA, Drake KL, Siddavatam P, Lawhon SD, Nunes JE, Gull T, Khare S, Everts RE, Lewin HA, Adams LG (2013) Systems biology analysis of Brucella infected Peyer's patch reveals rapid invasion with modest transient perturbations of the host transcriptome. PLoS One 8(12):e81719. https://doi.org/10.1371/journal.pone.0081719

Saikh KU, Khan AS, Kissner T, Ulrich RG (2001) IL-15-induced conversion of monocytes to mature dendritic cells. Clin Exp Immunol 126(3):447-455. https://doi.org/10.1046/j.1365-2249.2001.01672.x

Salcedo SP, Marchesini MI, Lelouard H, Fugier E, Jolly G, Balor S, Muller A, Lapaque N, Demaria O, Alexopoulou L, Comerci DJ, Ugalde RA, Pierre P, Gorvel JP (2008) Brucella control of dendritic cell maturation is dependent on the TIR-containing protein Btp1. PLoS Pathog 4(2):e21. https://doi.org/10.1371/journal.ppat. 0040021

Salcedo SP, Marchesini MI, Degos C, Terwagne M, Von Bargen K, Lepidi H, Herrmann CK, Santos Lacerda TL, Imbert PR, Pierre P, Alexopoulou L, Letesson JJ, Comerci DJ, Gorvel JP (2013) BtpB, a novel Brucella TIR-containing effector protein with immune modulatory functions. Front Cell Infect Microbiol 3:28. https://doi.org/ 10.3389/fcimb.2013.00028

Schlitzer A, McGovern N, Ginhoux F (2015) Dendritic cells and monocyte-derived cells: two complementary and integrated functional systems. Semin Cell Dev Biol 41:9-22. https://doi.org/10. 1016/j.semcdb.2015.03.011

Scholz HC, Hubalek Z, Sedlácek I, Vergnaud G, Tomaso H, Al Dahouk S, Melzer F, Kämpfer P, Neubauer H, Cloeckaert A, Maquart M, Zygmunt MS, Whatmore AM, Falsen E, Bahn P, Göllner C, Pfeffer M, Huber B, Busse HJ, Nöckler K (2008) Brucella microti sp. nov., isolated from the common vole Microtus arvalis. Int J Syst Evol Microbiol 58(2):375-382. https://doi.org/10.1099/ijs.0.65356-0

Scholz HC, Nöckler K, Göllner C, Bahn P, Vergnaud G, Tomaso H, Al Dahouk S, Kämpfer P, Cloeckaert A, Maquart M, Zygmunt MS, Whatmore AM, Pfeffer M, Huber B, Busse HJ, De BK (2010) Brucella inopinata sp. nov., isolated from a breast implant infection. Int J Syst Evol Microbiol 60(4):801-808. https://doi.org/10.1099/ ijs.0.011148-0

Scholz HC, Revilla-Fernández S, Al Dahouk S, Hammerl JA, Zygmunt MS, Cloeckaert A, Koylass M, Whatmore AM, Blom J, Vergnaud G, Witte A, Aistleitner K, Hofer E (2016) Brucella vulpis sp. nov., isolated from mandibular lymph nodes of red foxes (Vulpes vulpes). Int J Syst Evol Microbiol 66(5):2090-2098. https://doi.org/10.1099/ ijsem.0.000998

Seillet C, Belz GT (2013) Terminal differentiation of dendritic cells. Adv Immunol 120:185-210. https://doi.org/10.1016/B978-0-12417028-5.00007-7

Seleem MN, Boyle SM, Sriranganathan N (2010) Brucellosis: a reemerging zoonosis. Vet Microbiol 140(3-4):392-398. https://doi. org/10.1016/j.vetmic.2009.06.021

Sengupta D, Koblansky A, Gaines J, Brown T, West AP, Zhang D, Nishikawa T, Park SG, Roop RM 2nd, Ghosh S (2010) Subversion of innate immune responses by Brucella through the targeted degradation of the TLR signaling adapter, MAL. J Immunol 184(2):956-964. https://doi.org/10.4049/jimmunol. 0902008

Smither SJ, Perkins SD, Davies C, Stagg AJ, Nelson M, Atkins HS (2009) Development and characterization of mouse models of infection with aerosolized Brucella melitensis and Brucella suis. Clin Vaccine Immunol 16(5):779-783. https://doi.org/10.1128/CVI. 00029-09

Soruri A, Zwirner J (2005) Dendritic cells: limited potential in immunotherapy. Int J Biochem Cell Biol 37(2):241-245. https://doi.org/10. 1016/j.biocel.2004.07.003

Starr T, Ng TW, Wehrly TD, Knodler LA, Celli J (2008) Brucella intracellular replication requires trafficking through the late endosomal/ lysosomal compartment. Traffic 9(5):678-694. https://doi.org/10. $1111 / j .1600-0854.2008 .00718 . x$ 
Suraud V, Jacques I, Olivier M, Guilloteau LA (2008) Acute infection by conjunctival route with Brucella melitensis induces IgG+ cells and IFN-gamma producing cells in peripheral and mucosal lymph nodes in sheep. Microbes Infect 10(12-13):1370-1378. https://doi.org/10. 1016/j.micinf.2008.08.003

Surendran N, Hiltbold EM, Heid B, Akira S, Standiford TJ, Sriranganathan N, Boyle SM, Zimmerman KL, Makris MR, Witonsky SG (2012) Role of TLRs in Brucella mediated murine DC activation in vitro and clearance of pulmonary infection in vivo. Vaccine 30(8):1502-1512. https://doi.org/10.1016/j. vaccine. 2011.12 .036

Takeda K, Akira S (2015) Toll-like receptors. Curr Protoc Immunol 1(109):14.12.1-14.12.10. https://doi.org/10.1002/0471142735. im1412s 109

Tantibhedhyangkul W, Ben Amara A, Textoris J, Gorvel L, Ghigo E, Capo C, Mege JL (2013) Orientia tsutsugamushi, the causative agent of scrub typhus, induces an inflammatory program in human macrophages. Microb Pathog 55:55-63. https://doi.org/10.1016/j. micpath.2012.10.001

Traxler RM, Lehman MW, Bosserman EA, Guerra MA, Smith TL (2013) A literature review of laboratory-acquired brucellosis. J Clin Microbiol 51(9):3055-3062. https://doi.org/10.1128/JCM.00135-13

Underhill DM, Ozinsky A (2002) Toll-like receptors: key mediators of microbe detection. Curr Opin Immunol 14(1):103-110. https://doi. org/10.1016/S0952-7915(01)00304-1

Velásquez LN, Delpino MV, Ibañez AE, Coria LM, Miraglia MC, Scian R, Cassataro J, Giambartolomei GH, Barrionuevo P (2012) Brucella abortus induces apoptosis of human T lymphocytes. Microbes Infect 14(7-8):639-650. https://doi.org/10.1016/j.micinf.2012.02.004

Vermaelen K, Pauwels R (2005) Pulmonary dendritic cells. Am J Respir Crit Care Med 172(5):530-551. https://doi.org/10.1164/rccm. 200410-1384SO

von Bargen K, Gorvel JP, Salcedo SP (2012) Internal affairs: investigating the Brucella intracellular lifestyle. FEMS Microbiol Rev 36(3): 533-562. https://doi.org/10.1111/j.1574-6976.2012.00334.x

von Bargen K, Gagnaire A, Arce-Gorvel V, de Bovis B, Baudimont F, Chasson L, Bosilkovski M, Papadopoulos A, Martirosyan A, Henri S, Mège JL, Malissen B, Gorvel JP (2015) Cervical lymph nodes as a selective niche for Brucella during oral infections. PLoS One 10(4):e0121790. https://doi.org/10.1371/journal.pone.0121790

Wanke MM (2004) Canine brucellosis. Anim Reprod Sci 82-83:195207. https://doi.org/10.1016/j.anireprosci.2004.05.005

Wei P, Cui G, Lu Q, Yang L, Guan Z, Sun W, Zhao Y, Wang S, Peng Q (2015) A20 promotes Brucella intracellular growth via inhibition of macrophage cell death and activation. Vet Microbiol 175(1):50-57. https://doi.org/10.1016/j.vetmic.2014.11.006

Xavier MN, Winter MG, Spees AM, Nguyen K, Atluri VL, Silva TM, Bäumler AJ, Müller W, Santos RL, Tsolis RM (2013) CD4+ T cellderived IL-10 promotes Brucella abortus persistence via modulation of macrophage function. PLoS Pathog 9(6):e1003454. https://doi. org/10.1371/journal.ppat.1003454

Yamazaki S, Maruyama A, Okada K, Matsumoto M, Morita A, Seya T (2012) Dendritic cells from oral cavity induce Foxp $3^{+}$regulatory T cells upon antigen stimulation. PLoS One 7(12):e51665. https://doi. org/10.1371/journal.pone.0051665

Yoneyama H, Ichida T (2005) Recruitment of dendritic cells to pathological niches in inflamed liver. Med Mol Morphol 38(3):136-141. https://doi.org/10.1007/s00795-005-0289-0

Zhan Y, Vega-Ramos J, Carrington EM, Villadangos JA, Lew $\mathrm{AM}, \mathrm{Xu}$ Y (2012a) The inflammatory cytokine, GM-CSF, alters the developmental outcome of murine dendritic cells. Eur J Immunol 42(11):2889-2900. https://doi.org/10.1002/eji. 201242477

Zhan Y, Xu Y, Lew AM (2012b) The regulation of the development and function of dendritic cell subsets by GM-CSF: more than a hematopoietic growth factor. Mol Immunol 52(1):30-37. https://doi.org/10. 1016/j.molimm.2012.04.009

Zhang CY, Bai N, Zhang ZH, Liang N, Dong L, Xiang R, Liu CH (2012) TLR2 signaling subpathways regulate TLR9 signaling for the effective induction of IL-12 upon stimulation by heat-killed Brucella abortus. Cell Mol Immunol 9(4):324-333. https://doi.org/10.1038/ cmi.2012.11

Zhang K, Wang H, Guo F, Yuan L, Zhang W, Wang Y, Chen C (2016) OMP31 of Brucella melitensis 16M impairs the apoptosis of macrophages triggered by TNF- $\alpha$. Exp Ther Med 12(4):2783-2789. https://doi.org/10.3892/etm.2016.3655

Zhao Y, Hanniffy S, Arce-Gorvel V, Conde-Alvarez R, Oh S, Moriyón I, Mémet S, Gorvel JP (2018) Immunomodulatory properties of Brucella melitensis lipopolysaccharide determinants on mouse dendritic cells in vitro and in vivo. Virulence 2:0. https://doi.org/10. 1080/21505594.2017.1386831

Zwerdling A, Delpino MV, Barrionuevo P, Cassataro J, Pasquevich KA, García Samartino C, Fossati CA, Giambartolomei GH (2008) Brucella lipoproteins mimic dendritic cell maturation induced by Brucella abortus. Microbes Infect 10(12-13):1346-1354. https:// doi.org/10.1016/j.micinf.2008.07.035 